\title{
Percepção de povos tradicionais do Cerrado sobre a implantação do Parque Nacional da Chapada das Mesas, Maranhão
}

\section{Perception of the traditional Cerrado peoples about the implementation of the Chapada das Mesas National Park, Maranhão, Brazil}

\author{
Maria Lindalva Alves da Silva ${ }^{(\mathbb{D})}$; Maria de Fátima Veras Araújo ${ }^{\left(\mathbb{D}{ }^{2}\right.}$; Gonçalo Mendes da Conceição ${ }^{(\mathbb{D}}{ }^{3}$ \\ ${ }^{1}$ Mestre em Biodiversidade Ambiente e Saúde, Universidade Estadual do Maranhão, Caxias, Maranhão, lindalva.maria@ hotmail.com; ${ }^{2}$ Doutora em Geografia, \\ Professora do Centro de Ciências da Natureza, Universidade Estadual do Piauí, Teresina, Piauí, maria.fveras2018@gmail.com; 3Doutor em Zootecnia, \\ Professor do Programa de Pós-Graduação em Biodiversidade, Ambiente e Saúde, Centro de Estudos Superiores de Caxias, Universidade Estadual do \\ Maranhão, Caxias, Maranhão, doutorgoncalo@gmail.com.
}

\section{A R T I G O}

Recebido: 07/02/2019

Aprovado: 15/06/2019

Palavras-chave:
Áreas protegidas
Conflitos socioambientais
Domínio fitogeográfico
Unidade de Conservação

Key words:

Protected areas

Socio-environmental conflicts

Phytogeographic domain.

Conservation unit

\begin{abstract}
R E S U M O
O Parque Nacional da Chapada das Mesas, foi criado em 2005, com objetivo de proteger a diversidade florística, faunística, espécies endêmicas, atributos naturais, como a presença de 400 nascentes de rios e morrarias esculpidas pelo processo de intemperismo natural presentes na região conhecida como Chapada das Mesas localizada no domínio fitogeográfico de Cerrado, no Sul do Maranhão, Brasil. Alguns aspectos a serem abordados quando se cria uma unidade de conservação são os conflitos gerados pela limitação da exploração dos recursos naturais pelos moradores do lugar, onde se implantará áreas protegidas e a questão fundiária. Neste sentido, a pesquisa teve como objetivo investigar a participação dos moradores no processo de criação do Parque Nacional da Chapada das Mesas. A pesquisa foi descritiva, com aplicação de formulários a 40 moradores. Verificou-se que $77,5 \%$ residem no Parque antes de sua criação, $75 \%$ não participaram do projeto de implantação da unidade de conservação e $50 \%$ foram contra. Com a perspectiva de as famílias ficarem morando dentro do Parque e com a elaboração do Plano de Manejo, espera-se que os moradores compreendam a importância do Parque Nacional para preservação desse ecossistema e passe a apoiar sua implantação.
\end{abstract}

\begin{abstract}
A B S T R A C T
The Chapada das Mesas National Park was created in 2005 whit the objective of protecting the floristic, faunistic, diversity, endemic species, natural attributes, such as the presence of 400 river sources and morrarias carved by the process of natural weathering present in the region, known as Chapada das Mesas, located in the Cerrado phytogeographic domain, in the South of Maranhão, Brazil. Some aspect to be addressed when creating a conservation unit is the conflicts generated by the limitation of the exploration of natural resources by the residents of the place, where protected areas the land issue. In this sense, it is research had as objective investigate the participation of residents in the process of creating the Chapada das Mesas National Park. The research was descriptive, whit application of forms to 40 residents. Checked that $77.5 \%$ live in the Park. $75 \%$ did not participate in the project to implement the conservation unit and $50 \%$ were against. With the perspective of families living inside the conservation unit and with the elaboration of the Management Plan, the residents are expected to understand the importance of the National Park to preserve this ecosystem and to support its implementation.
\end{abstract}

\section{INTRODUÇÃO}

Neste sentido, Campos et al. (2016, p.107-108)

De acordo com o Sistema Nacional de Unidades de Conservação (SNUC), instituído através da Lei Federal no 9.985/2000, as unidades de conservação (UCs), são espaços territoriais restritos, criado pelo Poder Público em favor da preservação e/ou conservação da sua diversidade biológica (BRASIL, 2000a). altam que as UCs têm "o propósito de promover a conservação do ambiente a partir da manutenção dessas áreas e da implementação de ações sustentáveis face aos críticos níveis de degradação ambiental em que se encontram esses santuários ecológicos".

\section{Revista Verde}

ISSN 1981-8203

Pombal, Paraíba, Brasil v. 14, n.3, jul.-set, p.429-435, 2019

doi: $10.18378 /$ rvads.v14i3.6363 
Sobre UCs, Pereira e Diegues (2010) ressaltam que o manejo dos recursos naturais aliados aos conhecimentos de grupos humanos, conhecidos como povos tradicionais, contribui para a conservação in situ em áreas de preservação. De acordo com autores, essa configuração é um novo caminho para os países em desenvolvimento que estão em fase de expansão da política de criação de áreas protegidas.

Dessa forma, a política de criação de UCs pode aliar-se à presença das populações locais, que a partir de sua forma de vida ajudam na conservação dos sistemas ecológicos encontrados nesses ambientes, pois estes grupos humanos diferenciam-se quanto ao aspecto sociocultural, embora vivam de forma mais ou menos isolada de outros grupos sociais (DIEGUES; ARRUDA, 2001).

Segundo a política do SNUC (Sistema Nacional de Unidades de Conservação), é assegurada a participação efetiva das comunidades locais no processo de criação, implantação e gestão, visando à proteção dos recursos naturais necessários à subsistência de populações tradicionais, respeitando e valorizando o conhecimento e a cultura, promovendo-as social e economicamente (BRASIL, 2000b).

Nesta perspectiva, Diegues (2002, p. 141-151), infere que "os povos tradicionais possuem um acordo ético em relação ao meio ambiente, associado aos conhecimentos tradicionais, em que o manejo dos recursos naturais pode proporcionar a conservação do meio ambiente". Corroborando com este pensamento, Melo et al. (2018) destacam dentre os objetivos das UCs, a manutenção da riqueza biológica da fauna e da flora e a conservação dos atributos naturais que proporcionam atividades turísticas voltadas para a contemplação das belezas paisagísticas locais, movimentando a economia e gerando renda para aqueles que vivem nas proximidades destas áreas de proteção.

Ao correlacionar a relação de apego das populações tradicionais com a cultura do lugar onde se estabeleceram, faz-se necessário realizar estudos voltados sobre percepção. Sendo assim, Rodrigues et al. (2012), preconizam a importância da compreensão da percepção ambiental das comunidades em áreas de abrangências de unidades de conservação, como gestão compartilhada, pois estes grupos sociais podem atuar no apoio frente aos sistemas de gestão de áreas protegidas.

Okamoto (2002) entende que a percepção ambiental abrange a compreensão das inter-relações entre o meio ambiente e os atores sociais, ou seja, como a sociedade percebe o seu meio circundante, expressando suas opiniões, expectativas e propondo linhas de conduta. Assim, para o autor, estudos que se caracterizam pela aplicação da percepção ambiental, objetivam investigar a maneira como o homem enxerga, interpreta, convive e se adapta à realidade do meio em que vive, principalmente, em se tratando de ambientes instáveis ou vulneráveis socialmente e naturalmente (de forma visual ou através da expressão dos sentimentos).

Sobre a política de criação de áreas protegidas, o Maranhão conta com 26 UCs. Destas, 14 são estaduais e 12 federais, de categoria de Uso Sustentável e de Proteção Integral. As áreas estaduais compreendem: 10 Áreas de Proteção Ambiental (APA), três Parques Estaduais e uma Estação Ecológica; enquanto as de âmbito federal são três Parques Nacionais, uma Reserva Biológica, duas Áreas de Proteção Ambiental e seis Reservas Extrativistas. Quanto as UCs municipais, são registradas oficialmente quatro no
Instituto Chico Mendes de Conservação da Biodiversidade, com categoria de APA de Uso Sustentável (BANDERIA; DANTAS, 2013; ICMBio, 2019).

Dentre as áreas de proteção do Maranhão, o PNCM é classificado como Unidade de Conservação de Proteção Integral e apesar de ter sido implantado em 2005, ainda tem a presença de comunidades tradicionais, as quais sobrevivem da agricultura de subsistência e da criação de animais. Neste contexto, Marques et al. (2014a) ressaltam que a área de proteção deu um novo formato na vida destas pessoas. As autoras relatam que os habitantes da área de abrangência da nova UC vivem do extrativismo vegetal, agricultura familiar e criação de animais, as quais estariam sujeitas as fiscalizações e normas do ICMBio.

De acordo com Silva et al. (2017a), a criação do PNCM foi o resultado da mobilização de representantes da sociedade civil do município de Carolina, para impedir a construção de duas pequenas hidrelétricas nas Cachoeiras de São Romão e da Prata, paisagens de elevada beleza cênica, de atributos naturais e grande diversidade de espécies florísticas e faunísticas peculiares do Cerrado maranhense.

A área onde foi instituída a UC tem a presença de grupos humanos reconhecidos através do Decreto Federal $\mathrm{n}^{\circ}$ 6.040/2007, como comunidades tradicionais, pela sua forma histórica e cultural de sobrevivência e utilização dos recursos naturais para o sustento de seu núcleo familiar (BRASIL, 2007; SILVA et al., 2017b).

Na visão de Del Rio e Oliveira (1996), o SNUC garante em suas diretrizes, parâmetros entre as comunidades locais e a gestão dos parques na tomada de decisões, visando a gestão mais participativa dos atores sociais que vive no entorno e dentro das UCs que serão implantadas. O que os autores propõem, avalia-se o proposto nesta investigação científica, na qual se faz uma discussão sobre a criação da unidade de conservação e a forma de participação dos moradores das comunidades tradicionais do interior e entorno, se tiveram participação nas discussões envolvendo o processo de criação e implantação do recém-criado PNCM.

Para tanto, devem ser destacados alguns aspectos quanto à criação de UCs, dentre eles, os conflitos gerados pela limitação da exploração dos recursos naturais pelos moradores do lugar e a questão fundiária. Esta pesquisa justifica-se pelos conflitos gerados entre os moradores de dentro e no entrono do Parque e a gestão do ICMBio relacionados ao manejo e uso dos recursos naturais; a situação fundiária; benefícios de programas sociais como eletrificação para os povoados, construção de estradas vicinais, poços tubulares para abastecimento de água, dentre outras demandas sociais, que poderiam ser implementadas na área de abrangência do referido Parque.

Há de se ressaltar que a área onde foi instituído o PNCM tem presença comunidades tradicionais. Neste caso, o Parque Nacional, necessita de estudos que possibilitem caracterizar as demandas, minimizar os conflitos e promover a conservação de ambientes naturais ímpares. Assim, a pesquisa tem como objetivo investigar a participação dos moradores no processo de criação do Parque Nacional da Chapada das Mesas.

\section{MATERIAL E MÉTODOS}

O PNCM possui uma área de 160.046 ha, que compreende os municípios de Carolina, Riachão e Estreito, no estado do Maranhão. O objetivo de sua criação foi a 
preservação de ecossistemas naturais de grande relevância ecológica e beleza cênica locais, a realização de pesquisas científicas, e o desenvolvimento de atividades de educação ambiental e turismo ecológico (ICMBio, 2016).

O PNCM está localizado entre as coordenadas $7^{\circ} 19^{\prime} 0^{\prime \prime}$, de latitude $\mathrm{S}$ e $47^{\circ} 20$ '06' de longitude W (Figura 1).

Figura 1. Mapa de localização do Parque Nacional da Chapada das Mesas, estado do Maranhão, Brasil

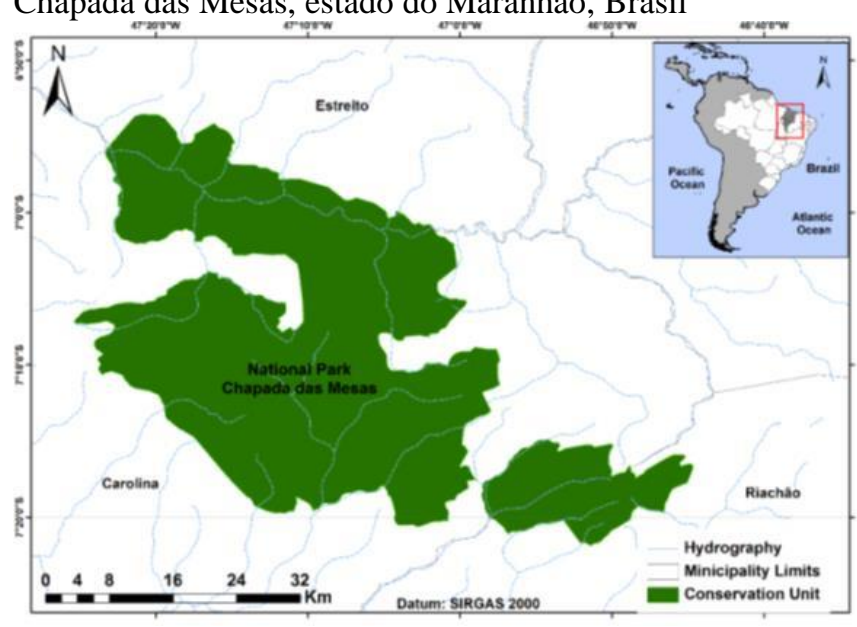

Fonte: ICMBio (2018).

O Parque Nacional tem como relevo predominante, o plano-ondulado, sendo que a maioria da área é formada por formas de relevo do tipo chapadas, com altitude basal em torno de $250 \mathrm{~m}$, com presença de morros de arenitos, variando entre $250 \mathrm{~m}$ nos vales e nas chapadas até $254 \mathrm{~m}$ (MMA, 2016a).

O clima da região caracteriza-se como tropical úmido, com duas estações bem definidas: verão seco, de maio a outubro, e inverno chuvoso, de novembro a abril. A temperatura média anual é $26,1^{\circ} \mathrm{C}$ e os totais pluviométricos anuais variam de 1.250 a $1.500 \mathrm{~mm}$ (MMA, 2016b). O PNCM encontra-se quase que na sua totalidade sobre solo latossolo amarelo e areias sedimentares (IBAMA, 2006a).

A região tem importante valor ecológico para a manutenção da biodiversidade brasileira, uma vez que é um ecótono de três domínios fitogeográficos: Cerrado, Amazônia e Caatinga, portanto, com potencial para abrigar níveis altos de riqueza e abundância de espécies da flora e da fauna (IBAMA, 2006b; MARQUES, 2012a). As diversas fitofisionomias presentes no PNCM, são feições de cerrado s.s. e campo sujo; as formações florestais incluem o cerradão e a mata seca; e as florestas marginais, formadas pelas matas de galeria, buritizais e veredas (MARQUES, 2012b). Em locais com solo mais rico, principalmente em topo de serras, há manchas de matas Semideciduais (MMA, 2016c).

Do ponto de vista metodológico, a pesquisa é de natureza descritiva, com abordagem quanti-qualitativa. Para Creswell (2012), as duas vertentes vislumbram posicionamentos diferentes da problemática que está sendo suscitada, permitindo um olhar mais amplo acerca dos questionamentos levantados, pois os aspectos quantitativos subsidiam os resultados numéricos e os qualitativos a compreensão e análise de maneira subjetiva.

Os procedimentos metodológicos foram divididos em duas etapas: i) Levantamento bibliográfico e visitas in loco, nas comunidades tradicionais no interior e entorno do Parque; e ii) Elaboração de formulário semiestruturado. As questões visavam obter as características socioeconômicas dos moradores, como: gênero, faixa etária, escolaridade, estado civil, renda mensal, tempo de residência no lugar; e informações peculiares sobre o processo de criação da UC, especificamente: estado de origem, município do povoado em que mora, se o morador é o dono ou não da propriedade, se participou de algum movimento de luta em prol da criação da área de proteção, se sabe o motivo da sua criação e se foi a favor.

Os formulários com 12 questões fechadas, foram aplicados aos chefes de famílias, em 40 domicílios de forma aleatória, no segundo semestre de 2016, situados nos povoados na área de abrangência do PNCM: Santo Antônio, Canto do Balaio, Canto do Porto, Mutum, Remanso, Fazenda Jurema, Alto Bonito, Anita Pires, Cachoeira da Prata, Cachoeira do São Romão; e ii) no seu entorno: Solta, São José dos Pereira e Fazenda Tapuio.

Para a realização da pesquisa foram obtidas as seguintes autorizações: i) autorização para atividades com finalidade científica número 54126-1, junto ao Instituto Chico Mendes de Conservação da Biodiversidade/Sistema de Autorização e Informação em Biodiversidade (ICMBio/SISBIO); ii) autorização junto ao Comitê de Ética de Pesquisa/Certificado da apresentação para Aplicação Ética (CEP/CAAE), com o número 57683316.5.0000.554, do Centro de Estudos Superiores de Caxias (CESC/UEMA); iii) Termo de Consentimento Livre e Esclarecido (TCLE) junto aos moradores para aplicação do formulário.

Os dados obtidos foram tabulados e demonstrados por frequência simples e relativa e por meio de gráficos para melhor compreensão e análise dos resultados.

\section{RESULTADOS E DISCUSSÃO}

Dentre os moradores de comunidades do Parque Nacional da Chapada das Mesas, constatou-se que 97,5\% são maranhenses e 2,5\% são do estado do Tocantins. Destes, $87,5 \%$ pertencem ao município de Carolina e $17,5 \%$ de Riachão. Embora o PNCM tenha sido implantado entre os municípios de Carolina, Riachão e Estreito. Em Estreito, segundo informações do ICMBio de Carolina, não há moradores na área de abrangência do Parque Nacional.

Castilho et al. (2009); Collins (2010) e Bruno et al. (2018) destacam que estes grupos sociais conseguem manter a relação de interação, percepção, manutenção de suas necessidades básicas, sentimento de pertencimento e permanência do lugar onde vivem com suas tradições culturais e o respeito ao ambiente, garantindo assim, a conservação dos recursos naturais.

O maior percentual de moradores é do sexo masculino, com $67,5 \%$. Outro fator que contribuiu foi o modelo de família encontrado nas comunidades pesquisadas, (que é o tradicional). Esses dados corroboram os estudos de Costa (2013), realizado sobre o conhecimento etnobotânico de moradores residentes no entorno da Floresta Nacional do Amapá, onde $75 \%$ das famílias eram chefiadas por homens.

Em geral, verificou-se que os moradores (Figura 2), possuem baixo nível de instrução, sendo $37,5 \%$ analfabetos ou semianalfabetos. Verifica-se que esse grupo de moradores não teve a oportunidade de ser escolarizado ou de continuar seus estudos, em virtude do longo distanciamento das comunidades e o deslocamento dos mesmos para zona urbana dos municípios. Outro motivo está relacionado a idade dos 
que participaram da pesquisa que tinham partir de 60 anos de idade.

Em relação à idade dos moradores, $25 \%$ dos entrevistados tinham 60 anos ou mais, e $22,5 \%$ tinham entre 30 a 39 anos (Figura 3).

Figura 2. Escolaridade de moradores de comunidades tradicionais do Parque Nacional da Chapada das Mesas, estado do Maranhão

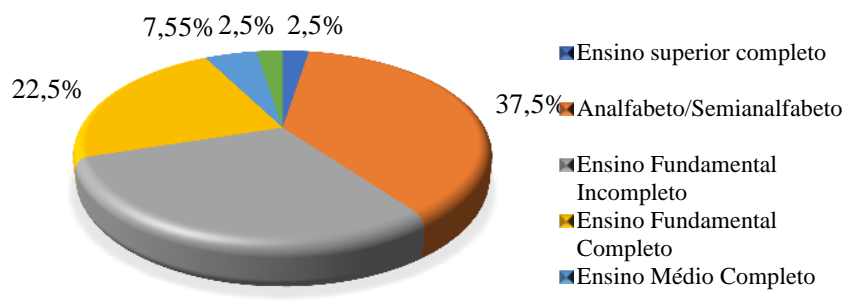

Figura 3. Faixa etária de moradores de comunidades tradicionais do Parque Nacional da Chapada das Mesas, estado do Maranhão

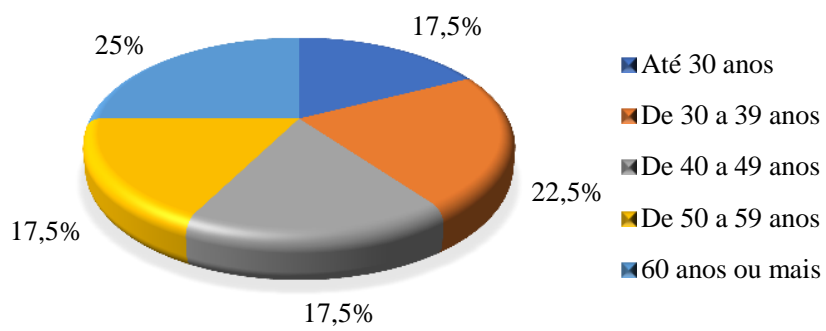

De acordo com a Figura 3, percebeu-se o envelhecimento das pessoas que vivem no campo, uma constatação que ocorre em muitas regiões do Brasil. A exemplo, destaca-se o estudo de Gonçalves et al. (2018) sobre o levantamento da base populacional na zona rural no município de Pelotas (RS) com a proposta de subsidiar políticas públicas de saúde a estas populações. A pesquisa demonstrou que a população idosa também prevalece sobre os mais jovens, o que colabora com o estudo amostrado no Parque Nacional, se tornando uma realidade em várias regiões brasileiras com êxodo rural de jovens, principalmente.

Quanto à constituição familiar, $57,5 \%$ são casados (religioso ou civil), enquanto que $22,5 \%$ são solteiros (Figura 4).

Figura 4. Estado civil de moradores de comunidades tradicionais do parque Nacional da Chapada das Mesas, estado do Maranhão.

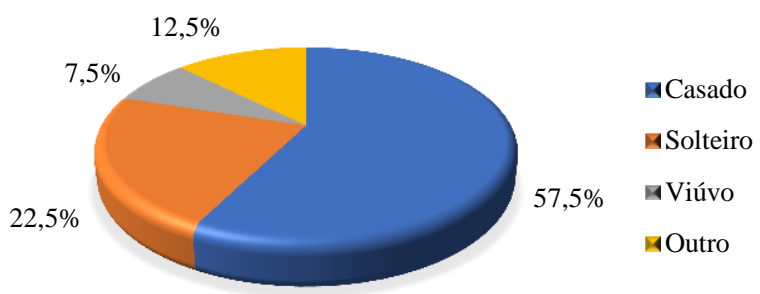

A constituição familiar é uma característica em grupos familiares que vivem em área rural, sendo comum o matrimônio ou união estável ainda muito jovem. A Figura 4 mostra o percentual de $70 \%$ entre as variáveis casados e outros, resultado semelhante ao estudo de Nóbrega et al. (2014), que ao traçar o perfil socioeconômico de agricultores familiares de Flores, município de Pombal (PB), 76\% dos entrevistados tinham o casamento ou união estável como principal estado civil.

Quanto à renda mensal, 75\% tem renda de até um salário mínimo, 7,5\% entre um a dois salários e $15 \%$ declararam não ter renda (Figura 5).

Figura 5. Renda familiar de moradores de comunidades tradicionais do Parque Nacional da Chapada das Mesas, estado do Maranhão.

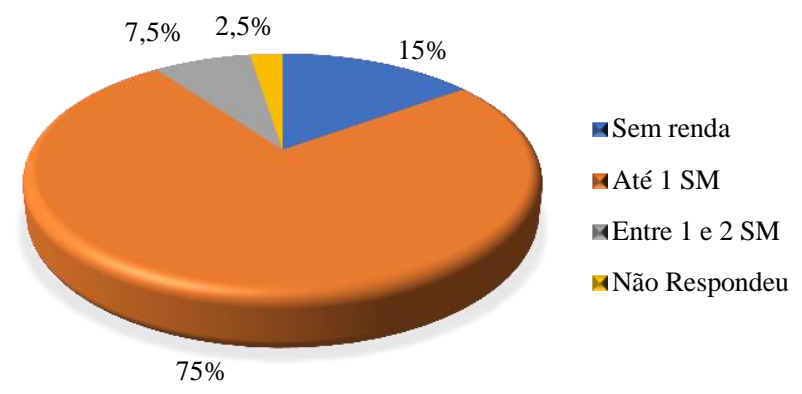

Na Figura 5, verifica-se que no geral os investigados são de baixa renda, recebendo até um salário mínimo. Os moradores sobrevivem da renda da agricultura familiar e da criação de animais. Wanderley (2009) ressalta que a agricultura familiar, além de ser exercida pelos membros de determinado grupo familiar, configura-se ao mesmo tempo como centro de produção e locação de trabalhadores. A agricultura familiar contribui para minimizar o êxodo rural, pois tem como meta, a permanência das pessoas em áreas rurais e colabora com o desenvolvimento local e regional com a produção de alimentos básicos (SERENINI; MALYSZ, 2015).

Conforme análise dos dados da Tabela 1, 77,5\% dos moradores residem na área de abrangência ou entorno do Parque há mais de 20 anos e 17,5\% até 10 anos.

Tabela 1. Tempo de moradia na área de abrangência do Parque Nacional da Chapada das Mesas, estado do Maranhão.

\begin{tabular}{ccc}
\hline & $\begin{array}{c}\text { Frequência } \\
\text { Absoluta (n) }\end{array}$ & $\begin{array}{c}\text { Frequência Relativa } \\
(\%)\end{array}$ \\
\hline Até 10 anos & 06 & $15 \%$ \\
De 11 a 20 anos & 03 & $7,5 \%$ \\
Mais de 20 anos & 31 & $77,5 \%$ \\
Total & 40 & $100 \%$ \\
\hline
\end{tabular}

Segundo declarações informais dos moradores, existem pessoas que residem nesta região há mais de cinquenta anos. Dessa forma, Santos (2012), quando se reporta ao território, indaga que os moradores da Chapada das Mesas fazem parte do contexto local, atuando como atores sociais no cenário que faz parte do sertão nordestino, ou seja, são caricaturas presentes na região onde residem.

Para Marques et al. (2014b), essas populações formatam esta terra ao longo dos anos, onde vêm construindo seu 
processo histórico e cultural. Os moradores dos povoados estudados têm laços de afetividade com ambientes naturais que utilizam como meio de sobrevivência, para produção de artesanato, cultivo de produtos agrícolas, no extrativismo vegetal, entre outras atividades que promovam seu sustento.

Entende-se que o grupo de atores sociais da pesquisa, estabeleceram vínculos afetivos com a região onde nasceram e constituíram suas famílias, além da forma como retira o sustento de todo núcleo familiar. A relação com o lugar não é apenas de exploração dos recursos do meio ambiente, mas de amor e harmonia com as paisagens naturais e dos ganhos socioambientais relacionados à qualidade de vida, a partir do contato direto com a biodiversidade local e das suas belezas cênicas.

Quanto à titularidade de suas propriedades, 57,5\% dos moradores declararam que são donos de suas propriedades. Dos que são donos, $60 \%$ possuem o título da terra com documentação comprobatória. Esses resultados demonstram as fragilidades das questões fundiárias em áreas de UCs, quando se tem pessoas residindo.

Os residentes da área do PNCM fundaram uma associação com a finalidade de defender seus interesses, mas por divulgarem informações inverídicas, geraram incertezas sobre os reais benefícios socioambientais advindos da criação do Parque (IBAMA, 2006b).

Na região sede de implantação do PNCM, verificou-se apreensão entre os moradores para regularização fundiária de suas terras. Quando se faz referência à existência de famílias em áreas de unidades de conservação, Marques (2012c) ressalta que há ambientalistas que defendem a permanência destas comunidades nas áreas protegidas, pois utilizam os recursos naturais para subsistência, causando baixo impacto ambiental.

Neste contexto, Little (2002, p. 21) relata:

[...] a questão dos direitos dos povos tradicionais passa pelo reconhecimento das respectivas leis consuetudinárias, que esses povos mantêm particularmente no que se refere a seus regimes de propriedade. Essa situação conduz ao reconhecimento da noção de "pluralismo legal", conceito que vem sendo trabalhado tanto dentro da antropologia, quanto no âmbito do direito (LITTLE, 2002, p.21).

As inferências das autoras supracitadas mostram a fragilidade da política de criação de áreas protegidas no Brasil. Necessário se faz repensar a metodologia de implantação no momento em que se cria uma UC, seja de âmbito, federal, estadual ou municipal, pois deve-se envolver efetividade nas pessoas que moram nas regiões de abrangência ou entorno da UC, para que despertem sua sensibilidade socioambiental, para a relevância da proteção de ambientes que estejam sofrendo pressões antrópicas.

Indagados sobre a sua participação nos movimentos organizados pela sociedade civil dos municípios de abrangência da UC, 75\% afirmaram que não se envolveram de forma efetiva, enquanto que $25 \%$ disseram que participaram de reuniões sobre a implantação de uma UC nesta região, conforme fala dos moradores registrado no Quadro 1.
Quadro 1. Opinião dos moradores sobre a participação em movimentos em prol da criação do Parque Nacional da Chapada das Mesas, estado do Maranhão.

\begin{tabular}{|c|c|}
\hline & Respostas dos moradores \\
\hline Morador A & $\begin{array}{c}\text { 'Nós não fomos convidados pelos } \\
\text { organizadores' }\end{array}$ \\
\hline Morador B & 'Não sabíamos de nada' \\
\hline Morador C & $\begin{array}{c}\text { 'Alguns vieram nas nossas casas e falaram } \\
\text { a respeito, mas não entendemos que } \\
\text { significava a criação deste Parque'. }\end{array}$ \\
\hline
\end{tabular}

As falas dos interlocutores remetem ao sentimento de impotência no processo de criação do PNCM. Diante deste cenário, Jeannot (2013), compreende a relevância de manter uma relação de cordialidade entre a população nas áreas de abrangências de UCs e a equipe gestora. No caso do PNCM, pode-se verificar que apesar da maioria dos moradores não participarem diretamente da mobilização social, constatou-se através de conversas informais a sensibilidade dos investigados ao cumprimento das normas do ICMBio, quanto ao uso dos recursos naturais dentro do Parque Nacional.

A partir destes argumentos, é possível inferir que os comunitários perceberam a importância da preservação da área ecológica para manutenção dos sistemas ecológicos, Assis et al. (2013, p.18) inferem que percepção é "o ato de traduzir e interpretar, que também são os fundamentos básicos da percepção ambiental, ferramenta muito utilizada pela gestão de áreas protegidas e em trabalhos que visem entender a relação da população de uma determinada região com o meio ambiente".

Arruda (1999) aponta alguns fatos que podem ser verificados quando se tem populações tradicionais em unidades de conservação, sobressaindo-se: i) a remoção de moradores; e ii) ausência de documentos legais de posse das terras. Essa análise evidenciou-se no momento das visitas nos domicílios em que se percebia a preocupação, quanto ao destino da situação fundiária.

Infere- se que houve a necessidade de traçar estratégias que envolvessem os moradores residentes no entorno da área de abrangência do PNCM, visando os ganhos ambientais com a criação da UC, considerada como prioridade máxima para conservação da biodiversidade, através de estudos apresentados ao Ministério do Meio Ambiente em 1998.

Sobre a motivação da criação da UC, em que 77,5\% alegaram não conhecer os objetivos para sua implantação. Medeiros e Young (2011) indicam alguns obstáculos durante o processo de efetivação de unidades de conservação, tais como os conflitos fundiários e a deficiência de infraestrutura básica, poucos funcionários que possam atuar na elaboração de estratégias de políticas de gestão, fiscalização e na construção de plano de manejo. A partir de informações não formais de alguns pesquisados, infere-se que a não participação dos moradores em mobilizações repercutiu na falta de informações sobre os motivos da implantação do projeto da criação do Parque Nacional da Chapada das Mesas.

Quanto ao posicionamento em relação à criação do Parque Nacional, verificou-se que $50 \%$ dos moradores não foram a favor; $40 \%$ responderam que sim; e $10 \%$ não opinaram (Tabela 2). A resistência dos moradores está no uso restrito dos recursos naturais. 
Tabela 2. Opinião dos moradores sobre a criação do Parque Nacional da Chapada das Mesas, estado do Maranhão.

\begin{tabular}{lcc}
\hline \multicolumn{1}{c}{ Respostas } & $\begin{array}{c}\text { Frequência } \\
\text { Absoluta (n) }\end{array}$ & $\begin{array}{c}\text { Frequência } \\
\text { Relativa (\%) }\end{array}$ \\
\hline Sim & 16 & $40 \%$ \\
Não & 20 & $50 \%$ \\
Não sabe/não respondeu & 04 & $10 \%$ \\
Total & 40 & $100 \%$ \\
\hline
\end{tabular}

Entende-se que a política de criação de unidades de conservação precisa rever o processo como um todo, especificamente a forma de desapropriação das pessoas que moram nestas áreas. Antes de apenas instituir a criação de uma UC, é preciso envolver os residentes e explicar a importância das políticas de conservação. A respeito de conflitos socioambientais, ocorrem "independente do contexto histórico e do espaço geográfico" (BRITO et al., 2011) e são inerentes à história humana (LEÃO; JULIANO, 2018a).

Dessa forma, políticas públicas conservacionistas sem a participação efetiva da sociedade civil, refletem uma construção permanente que rege o processo de criação de áreas protegidas no Brasil, que tem como consequências a maximização dos conflitos socioambientais dentro e/ou no seu entorno e a rejeição em sua criação. Para Hayward (2014); Leão e Juliano (2018b), os conflitos socioambientais necessitam de mediações entre a sociedade e natureza, quanto ao uso do espaço geográfico, bem como o direito da sua utilização pelos indivíduos em prol do desenvolvimento sustentável.

Nesta perspectiva, os desafios para conservação da biodiversidade do Parque são: a elaboração do Plano de Manejo da UC; e a preservação dessas áreas realmente protegidas por moradores e visitantes, ou seja, implementação efetivamente de ações que já existem legalmente e possíveis proposições locais.

Em 2018 iniciou-se a elaboração do Plano de Manejo do Parque, com a participação de representantes das famílias que residem dentro da UC, empresários de agências de turismo, secretários de Meio Ambiente das Prefeituras da área de abrangência do Parque, professores e alunos das Universidades públicas e privadas, organizações não governamentais.

\section{CONCLUSÃO}

Os moradores dos povoados que formam a região da Chapada das Mesas residem há mais de 20 anos nestas comunidades. Estes grupos sociais se estabeleceram no território com a prática da agricultura de subsistência e a criação de animais.

Os moradores não foram a favor da criação do Parque Nacional da Chapada das Mesas e a maioria não participou das campanhas de mobilização e não sabem os motivos de sua implantação. Uma das causas da não aceitação da implantação da unidade de conservação, pode estar relacionada aos conflitos sobre a posse de terras e a limitação do uso dos recursos naturais e, consequentemente, de suas atividades econômicas.

\section{AGRADECIMENTOS}

Ao Programa de Pós-Graduação em Biodiversidade, Ambiente e Saúde, do Centro de Estudos Superiores de
Caxias, Universidade Estadual do Maranhão (PPGBAS/CESC/UEMA), pela oportunidade da realização da pesquisa e ao Instituto Chico Mendes de Conservação da Biodiversidade (ICMBio) pela autorização da coleta de dados.

\section{REFERÊNCIAS}

ARRUDA, R. Populações tradicionais e a proteção dos recursos naturais em unidades de conservação. Ambiente \& Sociedade. v. 2, n. 5, p. 79-252, 1999. 10.1590/S1414753X1999000200007.

ASSIS, D. R. SOTERO, M.C.; PELIZZOLI, M.L. O papel da hermenêutica na concepção da percepção ambiental. Revista de Geografia, v.30, n.2, p.17-31, 2013.

BRASIL. Ministério do Meio Ambiente. Lei $n^{\circ}$ 9.985, de 18 de julho de 2000. Dispõe sobre o Sistema Nacional de Unidades de conservação, 2000. Diário Oficial da União. Poder Executivo, 2000.

BRASIL. Decreto Federal $n^{\circ} 6.040$, de 7 de fevereiro de 2007. Institui a Política Nacional de Desenvolvimento Sustentável dos Povos e Comunidades Tradicionais. Diário Oficial da União. Poder Executivo, 2007.

BRUNO, N. L.; PROFICE, C. C.; AGUIAR, P. C. B.; FERRAZ, M. I. F. Apego ao lugar e sustentabilidade ambiental em uma comunidade rural do sul do estado da Bahia, Brasil. Revista Gestão \& Sustentabilidade Ambiental, v. 7, n. 1, p. 206-234, 2018. 10.19177/rgsa.v7e12018206-234

BRITO, D. M. C; BASTOS, C. M. C. B.; DE FARIAS, R. T. S.; BRITO, D. C.; DIAS, G. A. C. D. Conflitos Socioambientais no Século XXI. PRACS. Revista Eletrônica de Humanidades do Curso de Ciências Sociais da UNIFAP, v.4, n.4, p.51-58, 2011.

BANDEIRA, I. C. N.; DANTAS, M. E. Geodiversidade do estado do Maranhão. In: BANDEIRA, I. C. N., DANTAS, M. E. (Eds.). Geoturísticos, Polos turísticos e Unidades de conservação. Teresina: CPRM, 2013, cap.9, p. 115-130.

CRESWELL, J. W. Qualitative Inquiry and Research Design: Choosing Among Five Approaches. Thousand Oaks, CA: Sage, 2012, 448p.

COLLINS, P. H. The New Politics of Community. American Sociological Association. v.75, n.1, p. 7-30, 2010. 10.1177/0003122410363293.

CASTILHO, M. A. de.; ARENHARDT, M. M; LE BOURLEGAT, C. A. Cultura e identidade: os desafios para o desenvolvimento local no assentamento Aroeira, Chapadão do Sul, MS. Interações, Campo Grande, v. 10, n. 2, p. 159169, 2009. 10.1590/S1518-70122009000200004.

COSTA, R. A. A identidade e o conhecimento etnobotânico dos moradores da Floresta Nacional do Amapá. 104f. Dissertação (Mestrado). Universidade Federal, 2013.

CAMPOS, A. A.; BATISTA, R. D. de C.; SANTOS, C. A.; SOUSA, M. F. L de. Educação e percepção ambiental na área do Parque Nacional Serra da Capivara-PI. Planeta Amazônia: Revista Internacional de Direito Ambiental e Políticas Públicas. Macapá, n. 8, p. 107-120, 2016. 
DIEGUES, A. C.; AARUDA, R. Saberes tradicionais e biodiversidade no Brasil. Brasília, DF. Ministério do Meio Ambiente, São Paulo: USP, 2001, 176p.

DIEGUES, A. C. O mito moderno da natureza intocada. São Paulo: NUPAUB - USP. Núcleo de Apoio à Pesquisa sobre Populações Humanas e Áreas Úmidas Brasileiras. Hucitec, 2002.176p.

DEL RIO, V.; OLIVEIRA, L. In: DEL RIO, V.; OLIVEIRA, L. (Eds.). Percepção Ambiental: a experiência brasileira. São Carlos: Ed. UFSCar, 1996. 34p.

GONÇALVES, H.; TOMASI, E.; TOVO-RODRIGUES, L.; BIELEMMAN, R. M; MACHADO, A. K. F.; RUIVO, A. C. O.; BORBOLOTTO,C. C.; JAEGER, G. P.; XAVIER, M. O.; FERNANDES, M. P.; MARTINS, R.C.; HIRSCHMANN, R.; SILVA, T. M.; ASSUNÇÃO, M. C. F. Estudo de base populacional na zona rural: metodologia e desafios. Revista de Saúde Publica. v. 52, n. 1, 2018. 10.11606/s15188787.201805200027.

HAYWARD, T. Equality and ecological space. Just World Institute, 2014, $26 \mathrm{p}$.

ICMBIO. Instituto Chico Mendes de Conservação da Biodiversidade. Nota Técnica $n^{\circ}$ 001/2016. Carolina/MA. Disponível em: <http://www.d1ij67glom3ric.cloudfront.net.> Acesso em: 27 Agosto 2019.

ICMBIO. Instituto Chico Mendes de Conservação da Biodiversidade. Dados Geoestatísticos das Unidades de Conservação $\quad$ Federal. Disponível em <http://www.icmbio.gov.br/portal/images/stories/servicos/geo processamento/DCOL/dados_tabulares/DadosGerais_UC_jul ho_2019.pdf >. Acessado em 27. mai. 2019

IBAMA. Instituto Brasileiro do Meio Ambiente e dos Recursos Naturais Renováveis. Projeto de diagnóstico socioeconômico-cultural-ambiental no Parque da Chapada das Mesas/ MA. MARQUES, A. R.; TCHAICKA, L.; LIMA, L. P. (Elab.). São Luís, 2006.

IBAMA. Relatório técnico do sobrevoo na área abrangida pelo Parque Nacional da Chapada das Mesas e entorno. LIMA, L. P.; MORAES, R. C. TCHAICKA, L. (Elab.). São Luís, 2006b.

JEANNOT, K. K. Análise participativa da efetividade do Parque Estadual do Ibitipoca. 79 f. Dissertação (Mestrado). Curso de Engenharia Florestal, UFLA, Lavras, 2013.

LITTLE, Territórios sociais e povos tradicionais no Brasil: por uma antropologia da territorialidade. Série Antropologia, v. 322, Brasília: Departamento de antropologia, 2002, p.2-32.

LEÃO, V. de M.; JULIANO, R. de F. A Identidade da Comunidade Tradicional e seu Papel em uma Unidade de Conservação do Brasil Central: Uma Perspectiva da Ecologia Política. Fronteiras, v.7, n.2, 2018, p. 273-289. 10.21664/2238-8869.2018v7i2.p273-289.

MMA, Ministério do Meio Ambiente. Parque Nacional da Chapada das Mesas. Nota Técnica 001/2016. Disponível em $<$ http://www.encurtador.com.br/pvPRS $>$ Acesso em: Acessado em 27. mai. 2019.
MARQUES, A. R. Saberes Geográficos Integrados Aos Estudos Territoriais sob a ótica da Implantação do Parque Nacional Da Chapada das Mesas, Sertão de Carolina/MA. 2012. 199f. Tese. (Doutorado). Universidade Estadual Paulista Faculdade de Ciências e Tecnologia. Presidente Prudente, 2012.

MARQUES, A. R.; FRENANDES, M. L. B.; BEZZERRA, J. F. R.; SILVA, Q. D. Abordagens sobre o território e a territorialidade das comunidades sertanejas do cerrado da chapada das mesas/MA. Campo-Território. Revista de Geografia Agrária. v, 9. n.19, p. 472-507, 2014.

MEDEIROS, R.; YOUNG C. E. F. Contribuição das unidades de conservação brasileiras para a economia nacional: Relatório Final. Brasília: UNEP- WCMC. 2011. 120p.

MELO R. S.; MONTEIRO, M. L.; BRITO A. S. Desenvolvimento Turístico e Sustentabilidade na Unidade de Conservação APA do Delta do Parnaíba (PI). Revista Brasileira de Ecoturismo, São Paulo, v.11, n.3, 2018, p.335361.

NÓBREGA, M. J. L. da. Perfil socioeconômico e ações dos agricultores familiares da comunidade rural de flores em Pombal, PB. INTESA, v. 8, n. 1, 2014, p. 44-56.

OKAMOTO, J. Percepção ambiental e comportamento: visão holística da percepção ambiental na arquitetura e na comunicação. São Paulo: Mackenzie, 2002. 261 p.

PEREIRA, B. E; DIEGUES, A. C. Conhecimento de populações tradicionais como possibilidade de conservação da natureza: uma reflexão sobre a perspectiva da etnoconservação. Revista Desenvolvimento e Meio Ambiente. n. 22, p. 37-50, 2010.

ROGRIGUES, M. L.; MALHEIROS, T. F.; FERNANDES, V.; DARÓS. T. D. A Percepção Ambiental Como Instrumento de Apoio na Gestão e na Formulação de Políticas Públicas Ambientais. Saúde Soc. São Paulo, v.21, suppl.3, 2012, p.96-110.

SANTOS, M. Metamorfose do espaço habitado. São Paulo: EDUSP, 2012, 136p.

SILVA, M.L. A; ARAÚJO, M.F.V.; CONCEIÇÃO, G.M. Identidade e modo de vida dos moradores do Parque Nacional da Chapada das Mesas, Maranhão, Brasil. Revista Biota Amazônia, v. 7, n. 4, p. 41-47, 2017. 10. 18561/2179-5746.

SERENINI, M. J.; MALYZS, S. Os desafios da escola pública paranaense na perspectiva do professor PDE. Produções Didático-Pedagógicas. In: SERENINI, M. J.; MALYZS, S. T. A importância da agricultura familiar na produção de alimentos. Cadernos PDE. v.2. UNESPAR. Paraná, 2014/2015.41p.

WANDERLEY, Maria N. B. O mundo rural como espaço de vida: reflexões sobre a propriedade da terra, agricultura familiar e ruralidade. Porto Alegre: Ed. UFRGS, 2009.328p. 